\title{
PLURALIDADE DE ATORES NO AMBIENTE CONSTRUÍDO: ANÁLISE DE PROJETO DE ARQUITETURA PELA ÓTICA DA ERGONOMIA
}

\author{
FERRER, Nicole (1); \\ BACCHI, Thais (2); \\ REITHLER, Luíza (3); \\ VILLAROUCO, Vilma (4) \\ (1) FACIMED, Mestra em Projeto de Arquitetura \\ e-mail:nicferrer.ara@gmail.com \\ (2) FACIMED, Mestra em Metodologias de Intervenção em Patrimônio Arquitetônico \\ e-mail: thais.bacchi@gmail.com \\ (3) FACIMED, Especialista em Gestão de Restauro \\ e-mail: luiza.reithler@gmail.com \\ (4) UFPE, Pós-doutora em Engenharia e Gestão do Conhecimento \\ e-mail: villarouco@hotmail.com
}

\begin{abstract}
RESUMO
A Ergonomia do Ambiente Construído se interessa pela forma com que as pessoas interagem com o ambiente, visto a partir de aspectos sociais, psicológicos, culturais e organizacionais. No entanto, o profissional de ergonomia atua quase que exclusivamente com o edifício já ocupado, avaliando o espaço enquanto no seu uso. Assim, o presente artigo analisa, através de um projeto desenvolvido como trabalho de conclusão de curso em Arquitetura e Urbanismo na Universidade Federal de Pernambuco, UFPE, a influência da ergonomia na formação do profissional de arquitetura, uma vez que o projeto aqui em pauta foi desenvolvido a partir de preceitos ergonômicos para melhor adequação do ambiente em preparação de usos futuros.
\end{abstract}

Palavras chave: ergonomia, projeto de arquitetura, múltiplos usuários.

\begin{abstract}
The Ergonomics of the Built Environment are interested in how people interact with their surroundings, seen from social, psychological, cultural and organizational perspectives. However, the ergonomics professional acts almost exclusively with the building already occupied, assessing the space during its use. Thus, the present paper analyzes, through a concluding project for an Undergraduate Degree in Architecture and Urbanism at the Federal University of Pernambuco, the influence of ergonomics in the training of the architectural professional, since the project in question was developed from ergonomic precepts to better suit the environment in preparation for future uses.
\end{abstract}

Keywords: ergonomics, architecture design, multiple users. 


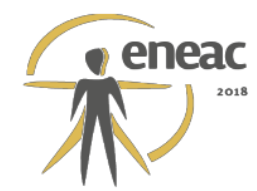

\section{INTRODUÇÃO}

Diversos estudos provam, e a história da humanidade corrobora com esta ideia, que é caráter instintivo do homem a busca por abrigo. A noção de se proteger para descansar e renovar as forças impulsionou os seres humanos a construírem as primeiras habitações e moradias. O ato de habitar o espaço "encontra sua definição nos dicionários como o ato de permanecer ou de tardar em um lugar, sendo talvez a manifestação arquitetônica mais antiga e extensiva de que se tem notícia, bem como o artifício que possivelmente nos permitiu sobreviver frente aos desafios do meio, quando outros animais maiores em tamanho e capacidade física sucumbiram" (REBELLO e LEITE, 2007).

Assim, o espaço físico ao ser projetado busca garantir ao homem, através de um ambiente artificial, a proteção aos riscos do ambiente exterior, promovendo uma estrutura funcional onde as atividades humanas possam ser abrigadas. Estas atividades normalmente são determinadas a partir dos valores culturais da sociedade em que o edifício está inserido.

A Ergonomia do Ambiente Construído, EAC, domínio especializado da área da Ergonomia, consiste em uma disciplina científica interessada na forma com que as pessoas interagem com o ambiente, visto a partir dos aspectos sociais, psicológicos, culturais e organizacionais. Para Mont'Alvão (2011), com a integração de conceitos como ambiente arquitetônico e ambiente do desenvolvimento das tarefas, em função das capacidades, habilidades e limitações humanas, a Ergonomia faz-se ferramenta necessária para o entendimento desse sistema, focando na interação humano-ambiente-atividade.

Em levantamento bibliométrico dos trabalhos científicos publicados nos anais dos principais eventos da área de EAC, Oliveira e Mont'Alvão (2015) olharam para publicações no ERGODESIGN (Congresso Internacional de Ergonomia e Usabilidades de Interfaces Humano - Tecnologia: Produtos, Informação, Ambiente Construído e Transportes) durante as edições de 2008 a 2012 e as edições do ENEAC (Encontro Nacional de Ergonomia do Ambiente Construído) de 2009 a 2013. De acordo com os autores "a pesquisa constatou que as metodologias mais utilizadas nas pesquisas de intervenção ergonômica em EAC foram: Intervenção Ergonomizadora (IE) - Moraes \& Mont'Alvão, 1998; Análise Ergonômica do Trabalho (AET) - Laville, 1997; Guérin, 2000; Vidal, 2003; Análise Macro Ergonômica do Trabalho (AMT) - Guimarães, 1999; Metodologia Ergonômica para o Ambiente Construído (MEAC) - Villarouco, 2007; e Avaliação Pós-Ocupacional (APO) - Ornstein, 1992".

Tais metodologias ergonômicas desenvolvidas para o ambiente construído, elencadas por Oliveira e Mont'Alvão, lidam com a análise do espaço posteriormente à sua construção. Além disso, a grande parte dos trabalhos científicos que fazem uso dessas metodologias as aplicam em espaços já edificados - para não se generalizar o fato ao dizer todos como via de regra. Desta forma, é possível concluir que o profissional de ergonomia atua quase que exclusivamente com o edifício já ocupado, avaliando o espaço enquanto no seu uso.

No entanto, é importante ressaltar o quão jovem é a vertente da análise do ambiente construído, dentro da disciplina da Ergonomia, que por si só pode ser considerada nova. Como dito por Villarouco (2002), a Ergonomia do Ambiente Construído "representa um braço mais recente da prática ergonômica". Assim, é possível enxergar a EAC como uma ciência que, aplicada ao ambiente construído, trabalha no sentido inverso ao fluxo direcional do projeto de arquitetura. Ela apresenta-se como ferramenta retroativa ao projeto arquitetônico, alimentando ou elencando possíveis recomendações espaciais para tipologias análogas.

Desta forma, o presente artigo tem como objetivo analisar, através de um projeto desenvolvido como trabalho de conclusão de curso em Arquitetura e Urbanismo na Universidade Federal de Pernambuco, UFPE, a influência da ergonomia na formação do profissional de arquitetura, uma vez que o projeto aqui em pauta foi desenvolvido a partir de preceitos ergonômicos para melhor adequação do ambiente em preparação de usos futuros. 


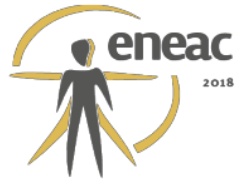

A EAC trabalha aqui como foco do projeto, angariando informações norteadoras para o desenvolvimento metodológico de um projeto de arquitetura de natureza hospitalar, focado para o uso de tratamento quimioterápico em usuários pediátricos.

\section{ERGONOMIA DO AMBIENTE CONSTRUÍDO}

O estudo do sistema ambiente-usuário constitui área significativa de interesse na busca da melhoria da qualidade de vida das pessoas. Essa melhoria é conferida ao ambiente construído pela ergonomia através da tecnologia de interface humano-ambiente, que se utiliza de vários métodos para avaliar esta relação em suas atividades (PAIVA, 2012). Assim, embora apresentando preocupações presentes em outras áreas do conhecimento, a ergonomia do ambiente extrapola as questões puramente arquitetônicas, focando seu posicionamento na adaptabilidade e conformidade do espaço às tarefas e atividades que neles se irão desenvolver.

Villarouco et al. (2005) referem que ao considerar os diversos aspectos envolvidos no ambiente construído, há a necessidade de uma abordagem sistêmica quando se trata de avaliar o projeto do ambiente sob a ótica da Ergonomia. Para os autores, uma completa avaliação ergonômica do ambiente abrange diversas variáveis, como o conforto ambiental, a percepção do usuário, as medidas antropométricas e a adequação dos materiais.

Ainda sobre o assunto, pode-se fazer alusão às pesquisas em ergonomia que, segundo Sommer (1973), investigam o grau de proximidade das pessoas, a organização humana em espaços grandes e pequenos e a influência da distribuição do mobiliário e equipamento (layout) na interação do homem com os diversos tipos de ambientes, fazendo-se uso de conceitos como espaço pessoal, territorialidade, multidão e privacidade.

Além disso, os aspectos envolvidos na adequação do ambiente devem advir do sentimento que o usuário experiência na interação cotidiana com o ambiente construído. Sua avaliação ultrapassa índices pré-estabelecidos, ou legislações, trazendo ao nível decisório o sentimento do homem, interfaceando os limites entre a razão e a emoção, tendo ainda como elemento mediador a bagagem cognitiva adquirida na trajetória vivencial do indivíduo. (VILLAROUCO, 2005).

Desenvolver esse olhar crítico e detalhista para entender, avaliar e modificar o ambiente construído é acima de tudo, entender que o produto do fazer projetual destina-se a abrigar o homem, que com toda sua bagagem de vivência, representa o personagem central do ato de habitar (em sua significação mais ampla).

\section{ARQUITETURA HOSPITALAR}

Para Bitencourt (2008), a concepção projetual de um Estabelecimento Assistencial de Saúde (EAS), denominação dada a qualquer edificação destinada à prestação de assistência à saúde à população, que demande o acesso de pacientes, em regime de internação ou não, qualquer que seja o seu nível de complexidade (RDC, Resolução da Diretoria Colegiada, No. 50, 2002), exige a atenção em fatores que vão além das novas tecnologias médicas. Sampaio (2005, p. 24) ainda afirma que os ambientes hospitalares devem ter, então, "adequadas temperaturas, trocas de ar e umidade, iluminação natural e artificial; contato interior/exterior com visualização do meio externo; jardins para contemplação e passeios e ruído adequados quando forem inevitáveis". Surge assim uma demanda por espaços pensados para cada caso específico, onde os consultórios atendam às características das diversas especialidades médicas, sendo cada ambiente configurado 


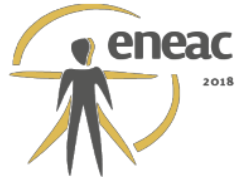

para atender às atividades específicas que abriga, com características adequadas ao seu uso.

O adoecimento pelo câncer, por exemplo, quando em uma criança, faz com que a vida do paciente passe por uma transformação rápida e intensa, vendo-se de repente em um espaço estranho com pessoas desconhecidas, sendo submetido a uma série de exames invasivos e dolorosos. Nesta situação, a criança tem a linha de continuidade de seu desenvolvimento subitamente rompida, sendo acuada pela sensação de perigo iminente de algo grave e temível, independentemente de sua idade e de sua capacidade de compreensão cognitiva da realidade que a rodeia (MENEZES et al., 2007).

O processo da busca pela cura requer uma adaptação à realidade da rotina do tratamento quimioterápico, tendo a criança que se habituar a uma vida limitante, de muitas restrições, submetendo-se a procedimentos muitas vezes dolorosos, tendo que sair da rotina de sua casa para a do hospital (MARQUES, 2004). De acordo com Perina (1997) apud Marques (2004), esta situação "submete a criança a uma série de consequências como: a desestruturação do sistema biopsicossocial, intensificação das angústias de morte, levando à mobilização de defesas psicológicas e ao redirecionamento das energias para adaptação à realidade hospitalar e aos seus procedimentos".

A terapêutica do câncer infantil, apesar de invasiva e complexa, não determina a hospitalização da criança. A criança com câncer pode ser tratada em nível ambulatorial, ficando a hospitalização apenas quando esse atendimento não for suficiente para suprir as demandas da doença (MELO e VALLE, 2010).

O tratamento oncológico ambulatorial consiste em retornos frequentes para exames, administração dos quimioterápicos, bem como consultas médicas e de enfermagem. Esta modalidade de tratamento evita a infecção hospitalar e diminui a ansiedade do afastamento repentino do lar e dos familiares. Entretanto, permanecem aspectos inevitáveis intrínsecos à doença e ao tratamento, como os sentimentos de medo e ansiedade, além de convivência com a dor, devido à realização de inúmeros procedimentos invasivos.

\section{O PROJETO DE ARQUITETURA}

O Hospital das Clínicas, HC, da Universidade Federal de Pernambuco não dispõe de espaço para a realização de tratamento quimioterápico em crianças (somente em pacientes adultos), apesar de disponibilizar atendimento oncológico pediátrico em seu quadro de serviços. Assim, um trabalho de conclusão de curso em Arquitetura e Urbanismo da mesma instituição propôs o desenvolvimento do projeto arquitetônico, em nível de anteprojeto, da Clínica de Quimioterapia Pediátrica da UFPE, hospital ambulatorial voltado para o desenvolvimento de tratamento de quimioterapia do público infanto-juvenil que o $\mathrm{HC}$ atende.

Idealizando-se de forma teórica tal proposta, o edifício objetiva suprir a demanda do Hospital das Clínicas, não necessitando o paciente de ser encaminhado para o IMIP, Instituto Materno Infantil de Pernambuco, hospital que supre as necessidades do HC no tratamento de seus pacientes. Desta forma, a proposta de um projeto arquitetônico apoiado fundamentalmente em critérios ergonômicos obtidos a partir de análises referenciadas da disciplina de Ergonomia do Ambiente Construído, estudos da literatura especializada na área e nas recomendações das normas da ANVISA.

Desta forma, organizando-se a listagem dos ambientes necessários para o projeto da Clínica de Quimioterapia Pediátrica da UFPE em 7 zonas distintas - circulação (em verde), social e área de espera (em amarelo), apoio aos pacientes e acompanhantes (em laranja), serviços e apoio aos funcionários (em azul), administração (em rosa), ambientes de tratamento (em roxo) e área lúdica com salão de eventos, brinquedoteca e pátio externo (em 


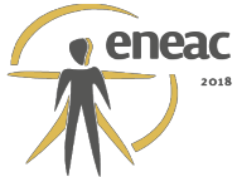

vermelho) -, têm-se uma distribuição de áreas dos espaços a partir de sua funcionalidade no ambiente, podendo ser visto graficamente nas Figuras 1 e 2, que ilustram o zoneamento da edificação

Figura 1 - Representação em planta baixa do pavimento térreo do zoneamento da Clínica de Quimioterapia Pediátrica da UFPE.

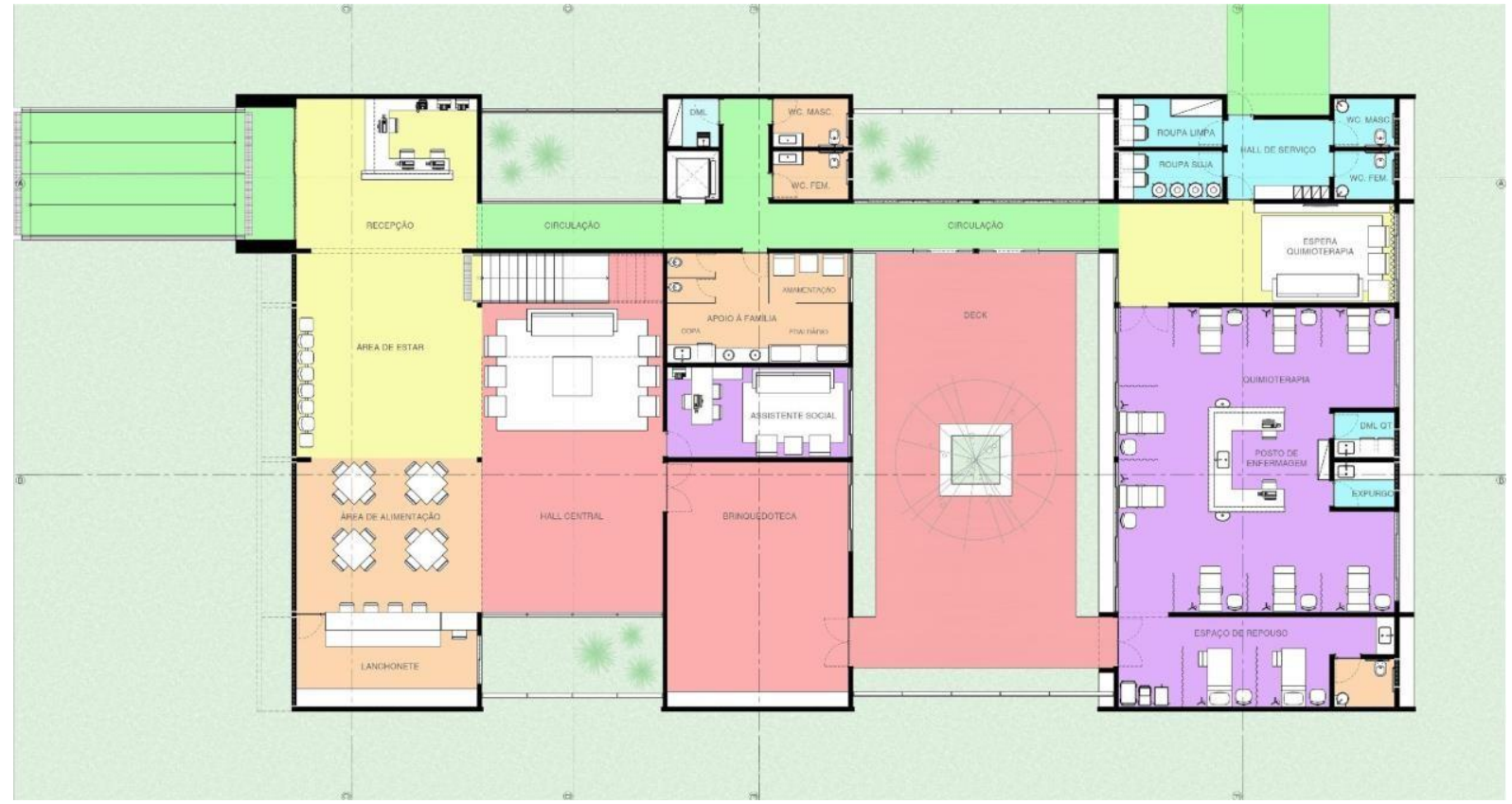

Fonte: Acervo dos autores.

Figura 2 - Representação em planta baixa do pavimento superior do zoneamento da Clínica de Quimioterapia Pediátrica da UFPE.
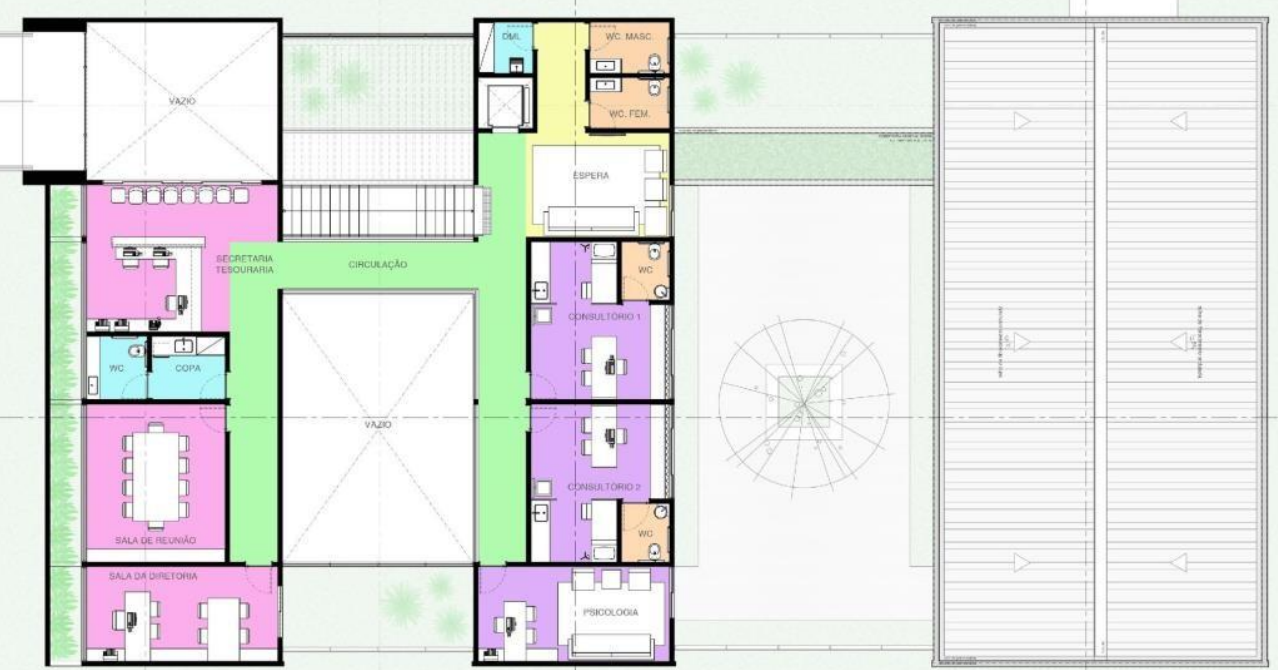

Fonte: Acervo dos autores. 


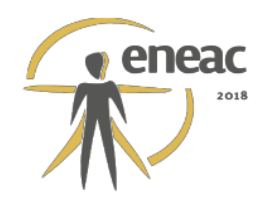

Diante das condições encontradas no presente objeto de estudo, percebe-se a necessidade e a importância de visualizar o ambiente construído como um conjunto interdependente de espaços, que se comunicam e interagem no desenvolvimento do trabalho. Além disso, fazse mister a observação deste espaço a partir do foco de percepção do usuário para o qual aquele ambiente se destina, com o intuito de melhorar as atividades e os espaços ocupados partindo-se de suas demandas específicas, criando uma maior eficiência no todo, na perspectiva de um melhor atendimento e acréscimo na qualidade da saúde desses usuários.

\section{ERGONOMIA APLICADA AO PROJETO DE ARQUITETURA}

A temática da relação entre fatores psicossociais, o processo de adoecimento e o tratamento necessário para a melhora do paciente vem ganhando destaque nos estudos da disciplina de Psicologia da Saúde. Passa então a ser utilizado o conceito do holismo, uma ideia que considera a pessoa como um todo, deixando de lado a tradicional compartimentalização do corpo em sistemas orgânicos. Isto significa que o homem passa a ser pensado como biopsicossocial, esteja ele saudável ou doente, tentando-se compreendêlo além da realidade física da necessidade de tratamento ao levar-se em conta seu bem estar, com suas implicações emocionais e sociais, em seu processo de melhora (MARQUES, 2004).

Tais conceitos permitem ao profissional de arquitetura com experiência em ergonomia visualizar seu objeto de estudo edificado como o cenário das atividades cotidianas de vida dos indivíduos. Deve-se pensar que o homem influencia o espaço e, em contrapartida, o espaço influencia o homem. Isso faz com que a relação sujeito-ambiente se torne recíproca, onde ambas as partes interagem em um nível extremamente próximo e íntimo, podendo afetar consideravelmente o usuário deste espaço em níveis psicossociais, culturais e físicos.

Além disso, é importante a consideração de que é de natureza humano a atividade em coletivo. Isso faz com que se tenha uma imensa pluralidade de atores do espaço construído, potencializando as diversas inter-relações entre as esferas do sujeito, ambiente e a atividade que ele irá desempenhar.

Um projeto arquitetônico, quando em fase de desenvolvimento, deve ser considerado como um protótipo do espaço, visto que nunca foi realizado antes. Por mais que se tenham tipologias e estudos de caso semelhantes, aquele objeto arquitetônico, com seu contexto específico e conectividade de elementos, é único.

Sendo assim, é necessário se pensar nos diversos atores do espaço, e como eles podem interagir no ambiente sem criar pontos de conflito desnecessários. Agravante ainda é o fato de que o paciente quando em tratamento tem um tempo de permanência longo no hospital. Isso influenciou a proposta a pensar no desenvolvimento de atividades lúdicas para divertimento, como também atividades de incentivo ao estudo e à criatividade. 


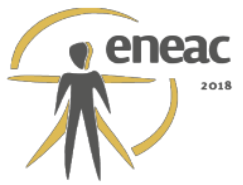

Figura 3 - Representação em corte da Clínica de Quimioterapia Pediátrica da UFPE.

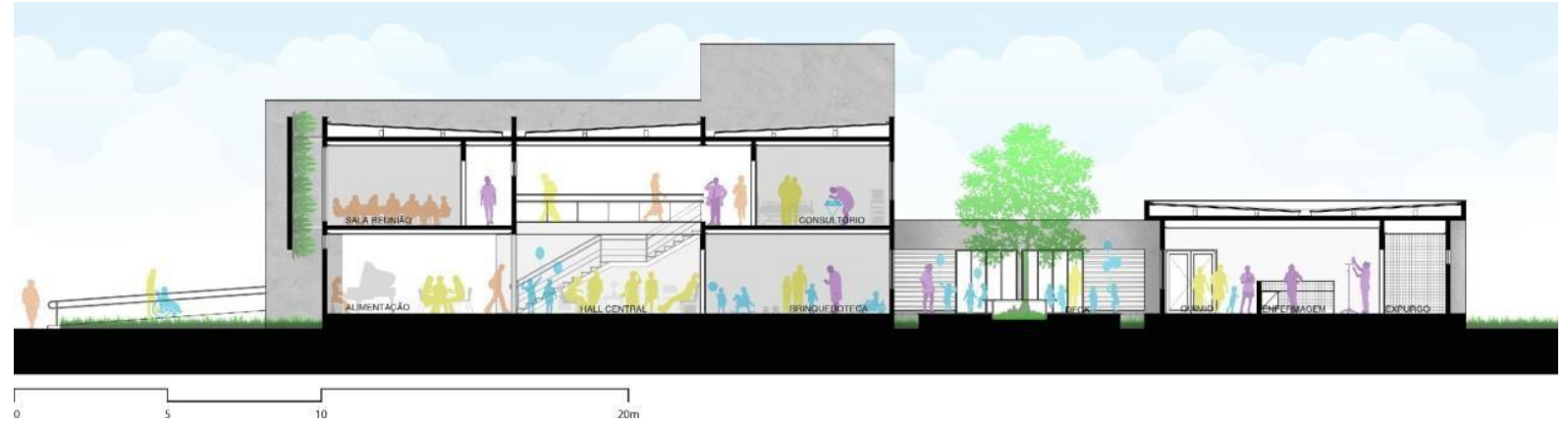

Fonte: Acervo dos autores.

Assim, o ponto principal do projeto foi o desenvolvimento de uma brinquedoteca como coração do edifício (referenciada na Figura 1 em vermelho). A este espaço se conectam um grande salão de espera, onde diferentes eventos podem ser desenvolvidos e um grande pátio externo, onde os usuários têm a possibilidade de se conectar com a natureza, como representado na Figura 3. Esse conjunto de ambientes possibilita aos diversos usuários, principalmente as crianças em tratamento, a possibilidade de desfocar a atenção da realidade de sua situação de saúde, facilitando o desenvolvimento de terapêuticas muitas vezes incômodas e dolorosas.

Figura 4 - Representação da Clínica de Quimioterapia Pediátrica da UFPE.

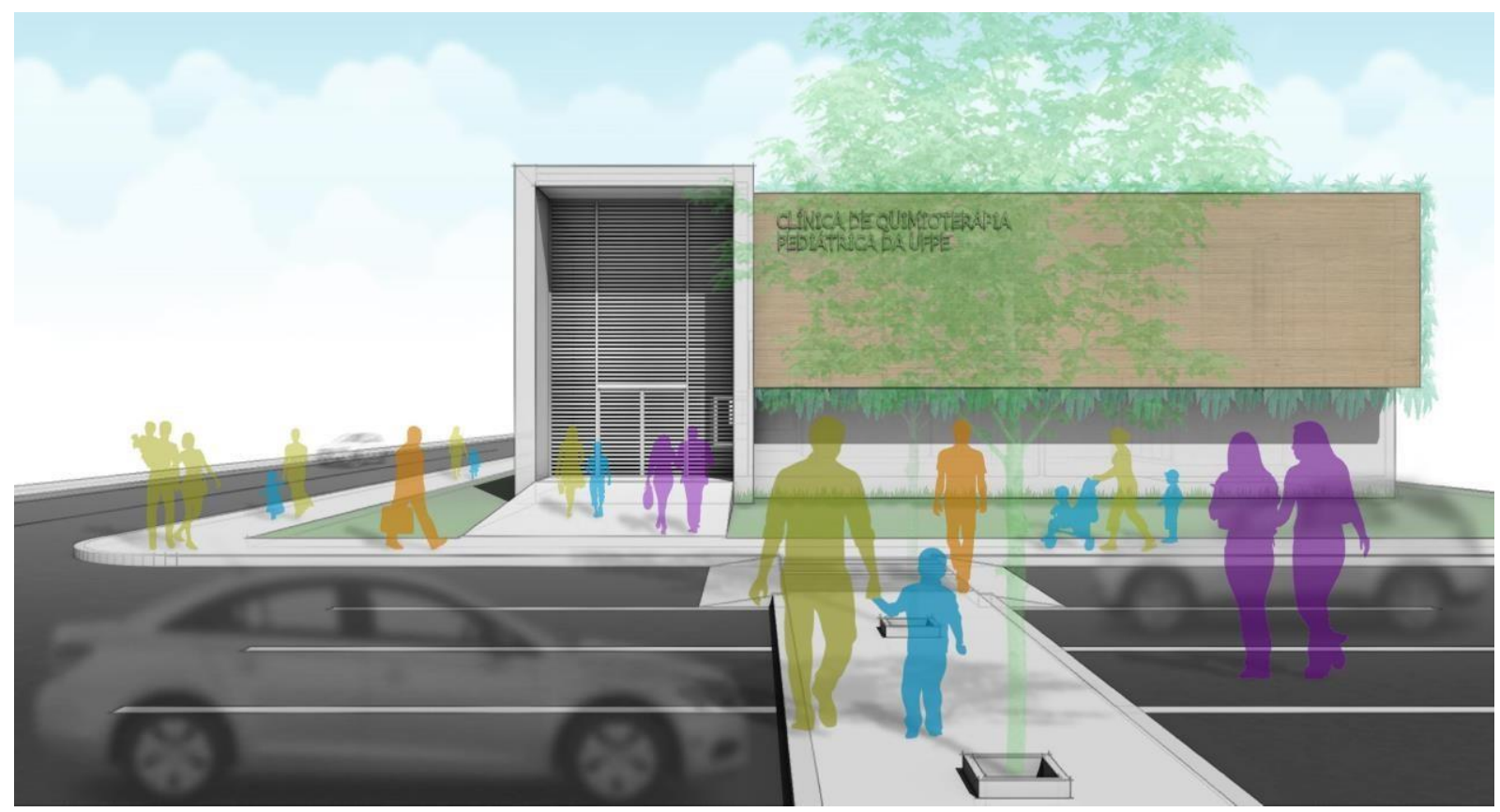

Fonte: Acervo dos autores.

Para tanto, faz-se necessário levar em consideração os diversos agentes envolvidos. Representados nas Figuras 3 e 4, os pacientes (em azul), os acompanhantes (em amarelo), ou funcionários da clínica (em laranja) e a equipe de saúde (em roxo) devem conviver harmonicamente no edifício. Isso faz com que as demandas espaciais de caráter coletivo, 


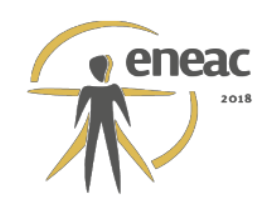

sejam elas no âmbito interno ou externo, requeiram uma maior atenção do profissional de arquitetura.

Faz-se mister no desenvolvimento do projeto a harmonia dos diversos elementos que entram em pauta, fazendo-se uso da ergonomia como veículo aglutinador de todas as facetas do projeto. É imperativo lembrar que, da mesma forma que o Desenho Universal ensina que há variedade na dimensão física, deve-se considerar que há ainda mais diversidade na dimensão cognitiva.

\section{CONCLUSÃO}

Permitir que a disciplina de Ergonomia seja restringida apenas à análise de espaços já construídos é limitar as potencialidades inerentes à sua natureza. O estudo da Ergonomia do Ambiente Construído tem muito a oferecer ao profissional de arquitetura em formação, fazendo com que ele seja treinado para olhar além das potencialidades plásticas e funcionais do projeto, uma vez que a ocupação e habitação do edifício devem ser o foco de seu desenvolvimento.

Olhar o espaço edificado através das lentes da Ergonomia do Ambiente Construído proporciona ao projetista uma expansão dos elementos a serem considerados no processo de projeto. Muitos são os fatores que passam a ter necessidade de consideração logo nos primeiros estágios da concepção do edifício, o que, em outros casos de metodologia projetual, apresentar-se-iam apenas em etapas de detalhamento e especificação, sendo por fim relegados pela impossibilidade de adequação.

Isso permite que o resultado final, que se mostra como um produto utilizado por um público específico, com toda a sua carga emocional, vivencial, social e cultural, seja uma construção amigável às atividades que abriga, otimizando as relações e favorecendo as suas funcionalidades inerentes.

\section{REFERÊNCIAS BIBLIOGRÁFICAS}

ANVISA - Agência Nacional de Vigilância Sanitária. Resolução da Diretoria do Colegiado № 220 (RDC № 220). Agência Nacional de Vigilância Sanitária. Brasília: ANVISA, 2004.

MARQUES, A. P. Câncer e estresse: um estudo sobre crianças em tratamento quimioterápico. Revista Psicologia Hospitalar. São Paulo - SP, 2004. v.2, n.2.

MELO, L de L.; VALLE, E. R. M. do. A Brinquedoteca como possibilidade para desvelar o cotidiano da criança com câncer em tratamento ambulatorial. Revista da Escola de Enfermagem. USP, 2010. vol. 44, no. 2. p. 517-25

MENEZES, C. N. B.; PASSARELI, P. M.; DRUDE, F. S.; SANTOS, M. A. dos; VALLE, E. R. M. do.

Câncer infantil: organização familiar e doença. Revista Mal-Estar e Subjetividade. Fortaleza-CE, 2007. v. 7, n.1.

MONT'ALVÃO, C. A ergonomia do ambiente construído no Brasil. In: Mont'Alvão, C.; Villarouco, V.. (Org.). Um novo olhar para o projeto: a ergonomia no ambiente construído. Teresópolis - RJ: 2AB, 2011, v. Único, p. 04-18.

OLIVEIRA, R. G.; MONT'ALVÃO, C. R. Metodologias utilizadas nos estudos de ergonomia do ambiente construído e uma proposta de modelagem para projetos de design de interiores. In: ERGODESIGN / USIHC - 15 Congresso Internacional de Ergonomia e Usabilidade de Interfaces Humano-Tecnologia, 2015, RECIFE. Anais do 15 Ergodesign - USIHC - Congresso Internacional de 


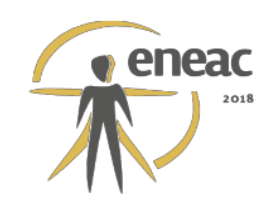

Ergonomia e Usabilidade de Interfaces. São Paulo: Blucher Design Proceedings, 2015. v. 02. p. 4548.

PAIVA, M. M. B. Ergonomia no ambiente construído de instituições para idosos - Estudo de caso em instituição brasileira e portuguesa. 2012. 217 f. Dissertação (Mestrado em Design) Departamento de Design, Universidade Federal de Pernambuco, Recife. 2012.

REBELLO, Y.; LEITE, M. A. D. As primeiras moradias. Agosto 2007. Revista Au. Edição 161. Disponível em: <http://www.au.pini.com.br/arquitetura-urbanismo/161/artigo58415-4.aspx>. Acesso em: 24/07/2017.

SAMPAIO, A. V. C. de F. Arquitetura hospitalar: projetos ambientalmente sustentáveis, conforto e qualidade; proposta de um instrumento de avaliação. $411 \mathrm{f}$. Tese (Doutorado em Área de Concentração: Estruturas Ambientais Urbanas) - Programa de Pós-Graduação em Arquitetura e Urbanismo, Faculdade de Arquitetura e Urbanismo, Universidade de São Paulo, São Paulo. 2005.

SOMMER, R. Espaço pessoal: as bases comportamentais de projetos e planejamentos. São Paulo, Ed. da Universidade de São Paulo, 1973.

VILLAROUCO, V. Avaliação ergonômica do projeto arquitetônico. In: Congresso Brasileiro de Ergonomia, 6, 2002, Recife. Anais. ABERGO. 2002.

VILLAROUCO, V.; ROZENDO, A. C.; ANDRADE, A. A. C.; ALMEIDA, E.; BARBOSA, M. P. Identificação de parâmetros para concepção de espaços ergonomicamente adequados à habitação social. In: 5 ERGODESIGN e 5o USIHC - 5o Congresso Internacional de Ergonomia e Usabilidade de Interfaces Humano-Tecnologia, 2005, Rio de Janeiro. Anais do 5o ERGODESIGN e 5o USIHC - 5o Congresso Internacional de Ergonomia e Usabilidade de Interfaces Humano-Tecnologia, 2005. 